\title{
Laughter up-regulates the genes related to NK cell activity in diabetes
}

\author{
Takashi Hayashi ${ }^{1}$, Satoru Tsuji ${ }^{2}$, Tadao Iburi $^{2}$, Tamiko TAmanaha $^{2}$, Keiko Yamagami ${ }^{2}$, Rieko Ishibashi ${ }^{2}$, \\ Miyo Hori ${ }^{1}$, Shigeko SaKamoto ${ }^{1}$, Hitoshi Ishil $^{2}$ and Kazuo Murakami ${ }^{1}$ \\ ${ }^{1}$ Bio-Laboratory, Foundation for Advancement of International Science, 586-9 Akatsuka-Ushigafuchi, Tsukuba, Ibaraki 305-0062, Japan; \\ and ${ }^{2}$ Diabetes Center, Tenri Yorozu-sodansho Hospital, 200 Mishima-cho, Tenri, Nara 632-8552, Japan
}

(Received 30 August 2007; and accepted 5 September 2007)

\begin{abstract}
To elucidate the sustainable effects of laughter on gene expression, we recruited type 2 diabetic patients who were in-patient for receiving self-management education and examined time-dependent regulation for gene expression by laughter. Two-day experiment was performed. On one day, the patients watched comic video and laughed together with hospital staffs. On the other day, they participated in an inpatient diabetes educational program. Blood samples were collected before and 1.5, $4 \mathrm{~h}$ after watching comic video or spending lecture time, and changes in gene expression were comprehensively analyzed by microarray technique. Of the 41,000 genes analyzed, the laughter relatively up-regulated 39 genes, among which, 27 genes were relatively increased in the expression for all the observation period after watching comic video. By functional classification of these genes, 14 genes were found to be related to natural killer cell activity. No genes were included that are directly involved in blood glucose regulation, though successive suppression of postprandial blood glucose levels was observed. These results suggest that the laughter influences the expression of many genes classified into immune responses, and may contribute to amelioration of postprandial blood glucose elevation through a modulation of NK cell activity caused by up-regulation of relating genes.
\end{abstract}

There are several studies on the physiological effects of laughter that have mainly focused on immunological aspects $(1,2,22,24)$ since Cousins, who had overcome his own disease, first reported that laughter was beneficial to the human body (5). On the other hand, negative emotions are well known to elevate blood glucose levels. With a hypothesis that laughter, which is one of the indicators for positive emotions, potentiate to suppress increases in blood glucose levels, we conducted a study on patients with type 2 diabetes, and the results showed that

Address correspondence to: Dr Takashi Hayashi, Foundation for Advancement of International Science, Bio-Laboratory, 586-9 Akatsuka-Ushigafuchi, Tsukuba, Ibaraki 305-0062, Japan

Tel: +81-29-836-6830, Fax: +81-29-836-6831

E-mail: hayashi@fais.or.jp laughter markedly suppressed the increase in the postprandial blood glucose (PPBG) levels (10) and influenced the gene expression profile in the peripheral blood leukocytes (11). Furthermore, our consecutive study suggested that laughter prevents the exacerbation of diabetic nephropathy (12).

In the present study, we analyzed the time-dependent changes in gene expression by laughter using a microarray technique, to identify responsible genes

T. Hayashi and S. Tsujii equally contributed to this study and were responsible for study design, execution, data analysis and preparation of the paper. Subject recruitment, intervention and data acquisition were performed in Diabetes Center, Tenri Yorozu-sodansho Hospital. Data acquisition and analysis were conducted in Bio-Laboratory, Foundation for Advancement of International Science. 
for the beneficial effect of laughter on blood glucose regulation in the patients with type 2 diabetes.

\section{MATERIALS AND METHODS}

Subjects. Ten type 2 diabetic patients who were in-patient for receiving self-management education and skill training (6 men and 4 women) with a mean $( \pm \mathrm{SD})$ age of $55.3 \pm 10.0$ years, body mass index of $24.1 \pm 4.2 \mathrm{~kg} \mathrm{~m}^{-2}$, and $\mathrm{HbA}_{\mathrm{lc}}$ of $7.7 \pm 0.9 \%$ participated in a 2-day experiment. The experimental protocol was approved by the medical ethics committee of Tenri Yorozu-sodansho Hospital (Nara, Japan). Before participation, the purpose and risks associated with this study were carefully explained to all of the subjects, and written informed consents were obtained.

Study design. All patients underwent blood collection to determine basal levels of blood glucose and gene expression before lunch, and took the same meal on consecutive days. Patient meals were individually adjusted in energy according to their desirable body weight and in the same proportion of carbohydrate, protein, fat and fiber to the total energy. After a meal on day 1 or day 2 of the experiment, the patients watched a comic show video which featured well-known Japanese comedians and laughed together with other patients and hospital staffs for $1 \mathrm{~h}$. On the other experiment day, they spent one tedious diabetes lecture hour after lunch devoid of laughing episodes (control). The subjects were randomly assigned to watch comic video either on the first day or the second day. To measure blood glucose, blood samples were collected immediately, 1.5 and $4 \mathrm{~h}$ after watching comic video or spending lecture time (corresponding to 2, 3.5 and $6 \mathrm{~h}$ after the start of the meal). To analyze gene expression, blood samples were obtained 1.5 and $4 \mathrm{~h}$ after watching comic video or spending lecture time.

Microarray hybridization and data acquisition. RNA samples from the five subjects who showed successive suppression of the increase in PPBG were mixed and then comprehensively analyzed by microarray technique. Total RNA was prepared from the blood samples using PAXgene Blood RNA Kit (Qiagen) and reverse-transcribed to cDNA containing a T7 RNA polymerase promoter sequence. Complementary RNA (cRNA) incorporated aminoallyl nucleotides were generated from the cDNA by in vitro transcription and labeled with cyanine $(\mathrm{Cy}) 3$ or Cy5 dyes $(14,16)$. Cy3-labeled cRNA from samples before watching comic video or spending lecture time was mixed with an equal amount of Cy5labeled cRNA from samples taken 1.5 or $4 \mathrm{~h}$ after watching comic video or spending lecture time for the analysis of the genes exhibiting relative changes in expression. The mixture was applied to the microarray spotted 41,000 genes (including transcripts) (Agilent Whole Human Genome), and hybridization was allowed to proceed for $17 \mathrm{~h}$ at $65^{\circ} \mathrm{C}$ as described by the manufacturer. After hybridization, the arrays were washed, and scanned using a confocal laser scanner (Agilent G2565BA). The fluorescence intensities on the scanned images were quantified, corrected for background, and normalized using global normalization methods based on the assumption that the median values of the fluorescence intensities of both samples were identical. Array data were deposited at the Gene Expression Omnibus (National Center for Biotechnology Information) with Accession No. GSE4901.

For the analysis of the genes exhibiting relative changes in expression, genes were selected which displayed differences of more than 1.25- and 1.5-fold, or 0.8 - and 0.67 -fold expression changes before and $1.5 \mathrm{~h}$ and $4 \mathrm{~h}$ after watching the comic video and those before and after spending lecture time, respectively.

\section{RESULTS}

The increase in the 2-h PPBG after watching the comic video was suppressed in 7 patients (mean: $\left.37.4 \pm 23.9 \mathrm{mg} \mathrm{dl}^{-1}, \mathrm{P}=0.028\right)$, but not in $3 \mathrm{pa}-$ tients. Successive suppression of PPBG for $4 \mathrm{~h}$ after watching the comic video was observed in 5 patients.

Of the 41,000 genes analyzed, the exposure to comic video induced relative changes in the expression of 40 genes. Thirty nine genes were relatively up-regulated and one was down-regulated. Among 39 up-regulated genes, 27 were relatively increased in the expression for all the observation period after watching comic video.

By functional classification of these genes exhibiting continuous increase in the expression, immune-related genes (15 genes) were most frequent (Table 1). Next in frequency were signal-transduction-related genes (7 genes). There were no genes included that should be directly involved in blood glucose regulation. Fourteen out of 15 immune-related genes are supposed to be connected with natural killer (NK) cell activity. 


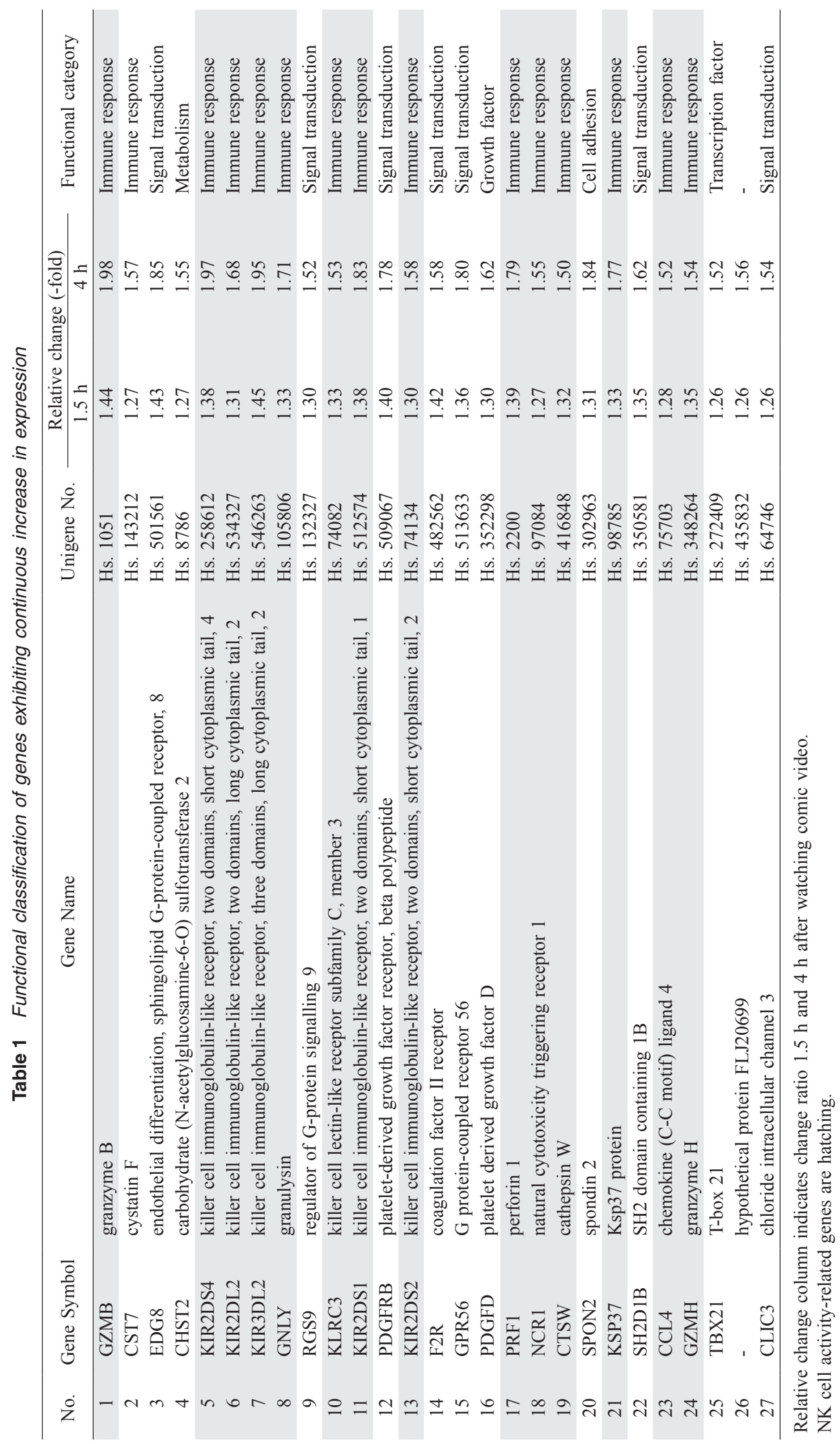




\section{DISCUSSION}

While genes that are directly involved in a blood glucose regulation were not discriminated in this study, the laughter up-regulated the many genes for immuno-functional molecules related to NK cell activity. The GZMB and GZMH genes encode granzymes $\mathrm{B}$ and $\mathrm{H}$, respectively, which are serine proteases involved in NK cell- or cytotoxic T lymphocyte (CTL)-mediated target cell lysis, and are present in cytoplasmic granules of these cells (13, $15,18,20)$. Perforin encoded by PRFI is a C9-like protein which can form lesions in the membranes of target cells, and is contained in the cytoplasmic granules of NK cells and CTLs $(13,17,26)$. This protein polymerizes in the presence of $\mathrm{Ca}^{2+}$ ions to cause rapid depolarization of the target cell membrane as a tubular complex forming large transmembrane pores (23). Granulysin encoded by GNLY is also presented in cytotoxic granules of NK cells and CTLs, and exert anti-microbial and anti-tumor activity (21). Cathepsin W encoded by CTSW is a novel cysteine protease presented in the endoplasmic reticulum of NK cells (25). KLRC3, NCRI and KIR family (KIR2DS1,S2,S4,L2,KIR3DL2) genes encode killer cell lectin-like receptor, natural cytotoxicity triggering receptor and killer cell immunoglobulin-like receptors, respectively, which should play in regulating NK cell functions $(4,8,22)$. KSP 37 encodes killer-specific secretory protein at late pregnancy, and may play important roles near parturition (9). CCL4 encodes a chemokine produced by neonatal NK cells in innate immune system (3).

Laughter is well known to enhance NK cell activity $(1,2)$. Since a comprehensive analysis was performed in this study to discriminate the genes regulated by laughter, NK cell activity was not measured. Recent studies have reported that adoptive transfer of NK cells into ob/ob mice resulted in a significant improvement in glucose intolerance (7) and an improvement of glucose intolerance by oral immune regulation towards liver extracted proteins was associated with elevated intrahepatic NK cells (6). Given that hepatic steatosis was also improved in the report, intrahepatic conditions in good shape, that is, keeping the good environment where constituent cells in the liver operate collaboratively in its functions of immuno-surveillance and nutrient metabolism, are important to adequate postprandial blood glucose regulation. This is consistent with the concept that intra-abdominal fat is responsible for insulin resistance, resulting in the metabolic syndrome that includes glucose intolerance. These findings lead the present data to the stringent speculations about the mechanism for the potential effect of laughter on blood glucose regulation. Laughter may contribute to amelioration of glucose intolerance through a modulation of NK cell activity caused by up-regulation of relating genes.

On the other hand, the expressions of genes which were functionally categorized in signal transduction were also continuously increased by the laughter. Four out of 7 genes in this category encoded the receptors, suggesting that the laughter may facilitate the communications between functional molecules in the body. However, the exact relationships between laughter and expression changes in some genes exhibiting relative change are still unclear.

Our previous study showed the genes involved in immune response and signal transduction were relatively decreased in their expression by laughter (11). The discrepancy against the relative increase found in the present study may be due to the differences in participants' demography, control conditions or experimental environment between these two studies. The control condition in the previous study was participating in a monotonous academic lecture instead of an inpatient diabetes educational program in this study. In addition, the place where the experiments were undertaken in the previous study was the city hall instead of the meeting room in the hospital in this study.

It is also possible that laughter exerts effects on blood glucose regulation by still unknown routes. Further studies are necessary for identifying the responsible genes for laughter-induced psychosomatic alterations like changes in blood glucose levels.

\section{Acknowledgements}

We are grateful to Mr. J. Takimoto, Mr. K. Ohgoe, and Mr. Y. Segawa for their excellent technical support. We are indebted to the volunteers who participated in this study.

\section{REFERENCES}

1. Berk LS, Tan SA, Napier BJ and Eby WC (1989) Eustress of mirthful laughter modifies natural killer cell activity. Clin Res 37, 115A. (Abstract)

2. Berk LS, Felten DL, Tan SA, Bittman BB and Westengard J (2001) Modulation of neuroimmune parameters during the eustress of humor-associated mirthful laughter. Altern Ther Health Med 7, 62-72, 74-76.

3. Bernstein HB, Kinter AL, Jackson R and Fauci AS (2004) Neonatal natural killer cells produce chemokines and suppress HIV replication in vitro. AIDS Res Hum Retroviruses 
20, 1189-1195.

4. Biassoni R, Cantoni C, Falco M, Verdiani S, Bottino C, Vitale M, Conte R, Poggi A, Moretta A and Moretta L (1996) The human leukocyte antigen (HLA)-C-specific "activatory" or "inhibitory" natural killer cell receptors display highly homologous extracellular domains but differ in their transmembrane and intracytoplasmic portions. $J$ Exp Med 183, 645650.

5. Cousins N (1976) Anatomy of an illness (as perceived by the patient). $N$ Engl J Med 295, 1458-1463.

6. Elinav E, Pappo O, Sklair-Levy M, Margalit M, Shibolet O, Gomori M, Alper R, Thalenfeld B, Engelhardt D, Rabbani E and Ilan Y (2006) Amelioration of non-alcoholic steatohepatitis and glucose intolerance in ob/ob mice by oral immune regulation towards liver-extracted proteins is associated with elevated intrahepatic NKT lymphocytes and serum IL-10 levels. J Pathol 208, 74-81.

7. Elinav E, Pappo O, Sklair-Levy M, Margalit M, Shibolet O, Gomori M, Alper R, Thalenfeld B, Engelhardt D, Rabbani E and Ilan Y (2006) Adoptive transfer of regulatory NKT lymphocytes ameliorates non-alcoholic steatohepatitis and glucose intolerance in ob/ob mice and is associated with intrahepatic CD8 trapping. J Pathol 209, 121-128.

8. Glienke J, Sobanov Y, Brostjan C, Steffens C, Nguyen C, Lehrach H, Hofer E and Francis F (1998) The genomic organization of $\mathrm{NKG} 2 \mathrm{C}, \mathrm{E}, \mathrm{F}$, and $\mathrm{D}$ receptor genes in the human natural killer gene complex. Immunogenetics 48, 163173.

9. Hayano C, Koi H, Ogawa K, Nagata K, Matsumoto Y, Nakamura $\mathrm{M}$ and Aso T (2002) Accumulation of CD16 cells with secretion of Ksp37 in decidua at the end of pregnancy. Am J Reprod Immunol 48, 57-62.

10. Hayashi K, Hayashi T, Iwanaga S, Kawai K, Ishii H, Shoji S and Murakami K (2003) Laughter lowered the increase in postprandial blood glucose. Diabetes Care 26, 1651-1652.

11. Hayashi T, Urayama O, Kawai K, Hayashi K, Iwanaga S, Ohta M, Saito T and Murakami K (2006) Laughter regulates gene expression in patients with type 2 diabetes. Psychother Psychosom 75, 62-65.

12. Hayashi T, Urayama O, Hori M, Sakamoto S, Nasir UM, Iwanaga S, Hayashi K, Suzuki F, Kawai K and Murakami K (2007) Laughter modulates prorenin receptor gene expression in patients with type 2 diabetes. J Psychosom Res 62, 703706.

13. Henkart PA (1985) Mechanism of lymphocyte-mediated cytotoxicity. Annu Rev Immunol 3, 31-58.

14. Hughes TR, Mao M, Jone AR, Burchard J, Marton MJ, Shannon KW, Lefkowitz SM, Ziman M, Schelter JM, Meyer MR., Kobayashi S, Davis C, Dai H, He YD, Stephaniants SB, Cavet G, Walker WL, West A, Coffey E, Shoemaker
DD, Stoughton R, Blanchard AP, Friend SH and Linsley PS (2001) Expression profiling using microarrays fabricated by an ink-jet oligonucleotide synthesizer. Nat Biotechnol 19, 342-347.

15. Lavie G, Leib Z and Servadio C (1985) The mechanism of human NK cell-mediated cytotoxicity. Mode of action of surface-associated proteases in the early stages of the lytic reaction. J Immunol 135, 1470-1476.

16. Luo L, Salunga RC, Guo H, Bittner A, Joy KC, Galindo JE, Xiao H, Rogers KE, Wan JS, Jackson MR and Erlander MG (1999) Gene expression profiles of laser-captured adjacent neuronal subtypes. Nat Med 5, 117-122.

17. Masson D and Tschopp J (1985) Isolation of a lytic, poreforming protein (Perforin) from cytolytic T-lymphocytes. $J$ Biol Chem 260, 9069-9072.

18. Masson D, Nabholz M, Estrade C and Tschopp J (1986) Granules of cytolytic T-lymphocytes contain two serine esterases. EMBO J 5, 1595-1600.

19. Nakajima A, Hirai H and Yoshino S (1999) Reassessment of mirthful laughter in rheumatoid arthritis. $J$ Rheumatol 26, 512-513.

20. Pasternack MS and Eisen HN (1985) A novel serine esterase expressed by cytotoxic T lymphocytes. Nature 314, 743-745.

21. Pena SV, Hanson DA, Carr BA, Goralski TJ and Krensky AM (1997) Processing, subcellular localization, and function of 519 (granulysin), a human late $\mathrm{T}$ cell activation molecule with homology to small, lytic, granule proteins. J Immunol 158, 2680-2688.

22. Pessino A, Sivori S, Bottino C, Malaspina A, Morelli L, Moretta L, Biassoni R and Moretta A (1998) Molecular cloning of NKp46: a novel member of the immunoglobulin superfamily involved in triggering of natural cytotoxicity. $J$ Exp Med 188, 953-960.

23. Podack ER, Young JD and Cohn ZA (1985) Isolation and biochemical and functional characterization of perforin 1 from cytolytic T-cell granules. Proc Natl Acad Sci USA 82, 8629-8633.

24. Takahashi $\mathrm{K}$, Iwase $\mathrm{M}$, Yamashita $\mathrm{K}$, Tatsumoto $\mathrm{Y}$, Ue H, Kuratsune H, Shimizu A and Takeda M (2001) The elevation of natural killer cell activity induced by laughter in a crossover designed study. Int $J$ Mol Med 8, 645-650.

25. Wex T, Buhling F, Wex H, Gunther D, Malfertheiner P, Weber E and Bromme D (2001) Human cathepsin W, a cysteine protease predominantly expressed in NK cells, is mainly localized in the endoplasmic reticulum. J Immunol 167, 21722178.

26. Young JD, Hengartner H, Podack ER and Cohn ZA (1986) Purification and characterization of a cytolytic pore-forming protein from granules of cloned lymphocytes with natural killer activity. Cell 44, 849-859. 
